\title{
Comparative and correlational analysis of the performance from 2016 crossfit games high-level athletes
}

\author{
João Francisco Barbieri'1,2, Renan Felipe Correia', Luz Albany Arcila Castaño', Douglas Vinicius Carvalho Brasil', \\ Alex Natalino Ribeiro'
}

\begin{abstract}
Background: CrossFit is a functional training modality created by Greg Glassman in 1995 in the United States. Such modality is characterized by the execution of complex and high intensity movements with the purpose of preparing the participant for the unpredictable. It is observed the exponential increase in CrossFit practice across the world, with this increase there are a consolidation of this modality with as a very peculiar sport modality, since as tasks to be performed in the competitions are made public just before the events happen. Few studies have focused on the determinants of competitive success in CrossFit, both morphologically and performance. Objective: This present study dedicated to investigate, in the existing literature and in the results of the 2016 championship, variables that can be predicted the performance of these athletes. Methods: The performance of 402016 - CrossFit Games finalists of both genders were analyzed in the morphological variables (weight, height, body mass index), performance and specific tests (Benchmarks and 1 MR tests). Results: We found that among male athletes, it was not possible to identify variables that could predict a classification. However, among the women, we identified some variables that correlated with classification, such as the Benchmark Filth 50 , Sprint performance of $400 \mathrm{~m}$ and maximal loads in the Clean and Jerk and Snatch exercises. Conclusion: It was attributed to the correlations found among women the smaller participation in the Games, this allowed physical characteristics as force to influence in the final position.
\end{abstract}

Key Words: CrossFit; Competition; High Level Athletes

\section{INTRODUCTION}

Created in 1995 by Greg Glassman, CrossFit (CF) is a functional training program that makes use of high-intensity power training (HIPT), a variation of high-intensity interval training (HIIT), to develop general fitness ${ }^{(1,2)}$. CF consists of weight lifts like squats, deadlifts, presses, as well as Olympic lifts and gymnastic movements, that are executed as quickly as possible and at high intensities ${ }^{(3)}$. Its exercise routines are famous for presenting standard exercise groupings, called benchmark workouts that carry either common female names or homage to names of fallen American soldiers ${ }^{(4,5)}$ (see table 1 ).

According to its creator's view, the benefits linked to CF's practice extend to a wide range of competencies: precision, agility, balance, coordination, cardiovascular and respiratory resistance, flexibility, power, speed, stamina and strength $^{(6)}$. However, there are few scientific studies on the adaptations promoted by this training method ${ }^{(7-11)}$. As well as the rate of injury in this modality ${ }^{(8,12-14)}$. Smith $^{(3)}$, in his study investigating 23 men and 20 women over 10 weeks of HIPT training demonstrated significant improvements in the participants' cardiorespiratory capacity as well as improvements in their body composition. However, Heirich ${ }^{(15)}$ found that 8 weeks of CF-based HIPT training were not able to alter the body composition of obese participants.

Although little is known about the adaptations caused by regular CF practice, it is a growing fitness program and sport. Its first official competition, the CrossFit Games (CFG), was held in 2007, with only 70 participants. In 2016, at the Reebok CrossFit Games (RCFG), this number surpassed the mark of 324.000 competitors, in a global scale event ${ }^{(16)}$.

There are still many knowledge gaps in how to best train these competitors and what skills are most needed during the competitions. In this line of research, Butcher ${ }^{(17)}$ conducted a study with CF Regionals and Open level competitors where he showed that performance in tests such as VO2max and Wingate were not correlated with performance in standard CF workouts, although correlation between Fran and Grace (CF's most common benchmark routines) and whole-body strength (1RM tests in specific exercises) tests was reported. In a study of 32 trained individuals, separated in two groups, with and without CF experience, Bellar ${ }^{(18)}$, found similar results.

Corresponding author: Luz Albany Arcila Castaño. R Gilberto Pattaro, 150, Casa 56, Residencial Burato, Campinas, SP, CEP 13084-375, Brazil. Email: Laarcila@utp.edu.co Cell Phone: +55 11993264796

${ }^{1}$ Faculdade de Educação Física, Universidade Estadual de Campinas (UNICAMP), Campinas (SP), Brasil.

Full list of author information is available at the end of the article.

Source of funding: None.

Submission date 28 August 2017; Acceptance date 11 October 2017; Publication date 30 November 2017 
In his study aerobic capacity, peak power and age did not correlate with CF performance between the two groups; while on the other hand, the individual's time of experience with CF positively influenced CF performance results.

In this sense, this present research investigated the results of RCFG 2016 participants, together with athlete self-reported morphological and functional information (performance in specific tests), in order to establish relationships between these variables and the athletes' ranking in this event.

\section{MATERIALS AND METHODS}

The present investigation is a cross-sectional exploratory study carried out with public data from $80 \mathrm{CF}$ competitors of both sexes. Results from the regional stages of RCFG 2016 were used. Parameters investigated were: classification results, years of CF practice, age, height, weight, body mass index (BMI), performance in standard benchmark workouts (Fran, Helen, Grace, Filthy 50, Fight Gone Bad), $400 \mathrm{~m}$ race, $5 \mathrm{~km}$ race, and strength tests. Due to its exploratory characteristics and use of public data, this research is exempt from the approval of a Research Ethics Committee.

\section{STATISTICAL ANALYSIS}

The Shapiro-Wilk test verified data normality. When confronted with parametric data, Pearson's $r$ correlation test was used to analyze the studied variables. In the same way, when confronted with non-parametric data, Spearman's $r$ correlation test was used. Studant's t-test compared the means of different data sets. A significance of $p<0.05$ was adopted in all tests

\section{RESULTS}

Table 2 presents the data regarding subjects' characteristics. Significant statistical differences were found for all variables, except practice time $(p=0.38)$.

Table 3 presents the correlations between competition performance ranking and their morphological characteristics and age. No significant correlations were found between these variables.

Table 4 presents correlations between competition ranking and benchmarks workout performance. Among the men, no correlations were found between these variables. Among the women, the Filthy 50 and $400 \mathrm{~m}$ run performances were strongly correlated $(\geq 0.7)$ with ranking.

Table 1. Description of the routines Benchmarks.

\begin{tabular}{|c|c|c|c|c|c|}
\hline Series & $\begin{array}{c}\text { Fran } \\
3\end{array}$ & $\begin{array}{c}\text { Helen } \\
3\end{array}$ & $\begin{array}{c}\text { Grace } \\
1\end{array}$ & $\begin{array}{c}\text { Filth } 50 \\
1\end{array}$ & $\begin{array}{l}\text { Fight Gone Bad } \\
3\end{array}$ \\
\hline \multirow{10}{*}{ Exercises } & \multirow{10}{*}{$\begin{array}{l}21-15-9 \text { Repetitions of thrusters } \\
\text { at } 43 \mathrm{~kg} \text { alternated with } 21-15-9 \\
\text { repetitions of bodyweight pull-ups }\end{array}$} & 400m Run & \multirow{10}{*}{30 Clean and jerks at $66 \mathrm{~kg}$} & 50 Repetitions of each: & $\begin{array}{l}1 \text { minute of each: ball } \\
\text { to wall shots at } 9 \mathrm{~kg}\end{array}$ \\
\hline & & $\begin{array}{l}21 \text { Kettlebell swing at } \\
24.5 \mathrm{~kg}\end{array}$ & & Box Jumps at $61 \mathrm{~cm}$ & $\begin{array}{l}\text { Sumo deadlift high-pulls } \\
\text { at } 34 \mathrm{~kg}\end{array}$ \\
\hline & & 12 Bodyweight pull-ups & & Jumping Pull Ups & Box jumps at $51 \mathrm{~kg}$ \\
\hline & & & & $\begin{array}{l}\text { Kettlebell Swings at } \\
16 \mathrm{~kg}\end{array}$ & $\begin{array}{l}\text { Push presses at } 34 \mathrm{kgs} \\
75 \mathrm{lb}(34.01 \mathrm{~kg})\end{array}$ \\
\hline & & & & Walking Lunges & Rowing (cal) \\
\hline & & & & $\begin{array}{l}\text { Knees to Elbows Push } \\
\text { Presses at } 20 \mathrm{~kg}\end{array}$ & \multirow[t]{5}{*}{ Rest } \\
\hline & & & & Back Extensions & \\
\hline & & & & Ball to Wall Shots at $9 \mathrm{~kg}$ & \\
\hline & & & & Burpees & \\
\hline & & & & Double Unders & \\
\hline
\end{tabular}

Table 2. Characterization and comparison among Crossfit competitors

\begin{tabular}{|c|c|c|c|}
\hline & $\begin{array}{c}\text { Men } \\
(n=40)\end{array}$ & $\begin{array}{l}\text { Women } \\
(n=40)\end{array}$ & $\begin{array}{c}\text { Comparison } \\
\mathbf{p}\end{array}$ \\
\hline Age & $25.65 \pm 2.53$ & $27.72 \pm 3.63$ & $0.00 *$ \\
\hline Time of practice (years) & $3.64 \pm 1.65$ & $3.46 \pm 0.1$ & 0.38 \\
\hline Height $(\mathrm{cm})$ & $176.59 \pm 5.27$ & $164.27 \pm 5.63$ & $0.00 *$ \\
\hline Weight (kg) & $88.27 \pm 5.21$ & $64.7 \pm 4.43$ & $0.00 *$ \\
\hline $\mathrm{Bmi}\left(\mathrm{kg} / \mathrm{cm}^{2}\right)$ & $28,30 \pm 1,17$ & $23.99 \pm 1.32$ & $0.00 *$ \\
\hline
\end{tabular}

Note: * Significant correlation $(p<0.05)$ 
Table 3. Correlation between Ranking and morphological characteristics

\begin{tabular}{lcc}
\hline & Men's & Women \\
\hline Ranking x Age & -0.09 & 0.10 \\
Ranking x Height & -0.11 & -0.20 \\
Ranking x Weight & -0.09 & -0.21 \\
Ranking x IMC & 0.02 & -0.01 \\
\hline
\end{tabular}

Note: *Significant correlation $(p<0.05)$

Table 4. Correlation between rankings, Benchmarks and Racing

\begin{tabular}{lccccc}
\hline & \multicolumn{2}{c}{ Mens's } & & \multicolumn{2}{c}{ Women } \\
\cline { 2 - 3 } \cline { 5 - 6 } & N & Correlation & & N & Correlation \\
\hline Ranking x Fran & 25 & $-0,13$ & & 27 & 0.08 \\
Ranking x Helen & 17 & 0.00 & & 12 & -0.21 \\
Ranking x Grace & 24 & 0.00 & & 26 & 0.19 \\
Ranking Filth x 50 & 13 & 0.42 & & 9 & $0.77 *$ \\
Ranking x Fight gone bad & 16 & -0.16 & & 15 & -0.29 \\
Ranking x 400m sprint & 14 & 0.06 & & 12 & $0.69 *$ \\
Ranking running x 5k & 15 & 0.42 & & 14 & 0.44 \\
\hline
\end{tabular}

Note: * Significant correlation $(p<0.05)$

Table 5. Correlation between Ranking and Maximum Force Tests

\begin{tabular}{lccccc}
\hline & \multicolumn{2}{c}{ MEN'S } & & \multicolumn{2}{c}{ WOMEN } \\
\cline { 2 - 3 } \cline { 6 - 7 } & $\mathbf{N}$ & Correlation & & $\mathbf{N}$ & Correlation \\
\hline Clean and Je rank rk x & 30 & -0.04 & & 36 & $-0.39 *$ \\
Ranking x snatch & 31 & -0.14 & & 36 & $-0.42 *$ \\
Ranking x Deadlift & 28 & 0.33 & & 32 & -0.08 \\
Ranking x Back Squat & 29 & 0.07 & & 35 & -0.15 \\
Pull-ups rank x & 23 & -0.16 & & 20 & -0.26 \\
\hline
\end{tabular}

Note: $*$ Significant correlation $(p<0.05)$

Table 5 presents correlations between ranking and physical tests. Among the men, no significant correlations were observed between championship classification and performance in the physical tests. Among women, we can identify two significant weak negative correlations between championship classification and performance in the clean and jerk and snatch tests.

\section{DISCUSSION}

In a recent study, Butche ${ }^{(17)}$ aimed to find correlations between physiological variables and performance on specific CF benchmarks workouts. He evaluated $14 \mathrm{CF}$ competitors' performances in Grace, Fran, Cindy, and CF-Total (a performance indicator that sums the following lifts: Squat, Overhead Press, and the Deadlift), in relation to performances in VO2max and Wingate tests. He found that the athletes' CF-Total and anaerobic threshold correlated significantly with performance in Grace and Fran. In light of this information, we are led assume that the adaptive characteristics of CF athletes are more focused on aspects of strength and use of the lactic anaerobic metabolism, in which case the best performers in the benchmark workouts would tend to rank higher in competitions. However, in relation to male subjects, our data showed that benchmark workout performance did not correlate with competition ranking, thus contracting Butcher's results ${ }^{(17)}$. The same is true for most female athletes' variables, with just few exceptions.

We highlight that female subjects showed a positive correlation between Filthy 50 benchmark workout, $400 \mathrm{~m}$ run time, and RCFG 2016 final standings. Both routines draw heavily from lactic and a lactic anaerobic metabolic sources, just like many of the exercises performed in CF competitions. The lack of correlation for these same variables regarding male subjects is surprising. We attribute this fact to the larger number of male participants in the RCFG $2016^{(19)}$, which may have increased competitiveness level among the men. We assume it is safe to hypothesize that with the increase in participation and specialization of female CrossFit athletes, these correlations will no longer be significant, since all participants will reach very close performance levels, just like as shown with the male athletes.

Although information on CF athletes' body composition is scarce, some studies have been dedicated on investigating changes in anaerobic resistance ${ }^{(20)}$ and body composition across $\mathrm{CF}$ training ${ }^{(3)}$. In this study, we found that BMI between men and women was significantly different. Although merely on speculative grounds, we could attribute the high BMI among men to a high lean-mass/bodyweight ratio. On the opposite hand, women presented a much lower BMI, probably linked to a lower lean-mass/bodyweight ratio. Still, this variable did not correlate with the athletes' performance in the RCFG 2016.

Some limitations must be pointed regarding the findings of this present study, because it is a study that used self-reported and public data, the reliability of these dates should be viewed with caution.

\section{CONCLUSION}

We found that, among men, there was no relationship between the variables investigated. We attribute this fact to the physical homogeneity of the male subjects, but not necessarily to their degree of sport specific specialization, since inconsistencies are easily found in each athlete's performance in the various individual CF disciplines. Among female athletes, we found significant correlations between some benchmark workouts and final ranking, showing that stronger athletes, more adapted to training routines that require use glycolytic metabolic pathways, emerge at the top of competition classification rankings. 


\section{AUTHOR'S CONTRIBUTION}

Acquisition of data and drafting the manuscript; JFB, RACS, analyzed and interpreted of data; LAAC, JFB, DVCB: Review the literature and wrote; DVCB, ANR: conceived and designed the experiments, final approved of the version to be published.

\section{CONFLICT OF INTEREST}

There is not.

\section{AUTHOR DETAILS}

${ }^{2}$ Faculdade Max Planck (FMP), Indaiatuba (SP), Brasil

\section{REFERENCES}

1. What is Crossfit? [Internet]. 2016 [cited 12/10/2016]. Available from: https://www.crossfit.com/what-is-crossfit.

2. Glassman G. What is crossfit. Retrieved from. 2002.

3. Smith MM, Sommer AJ, Starkoff BE, Devor ST. Crossfit-based high-intensity power training improves maximal aerobic fitness and body composition. Journal of strength and conditioning research / National Strength \& Conditioning Association. 2013;27(11):3159-72.

4. Glassman G. Benchmark Workouts. The CrossFit Journal Articles. 2003(13):1-5.

5. Paine J, Uptgraft J, Wylie R. CrossFit study. Command and General Staff College. 2010:1-34.

6. Partridge JA, Knapp BA, Massengale BD. An investigation of motivational variables in CrossFit facilities. Journal of strength and conditioning research / National Strength \& Conditioning Association. 2014;28(6):171421

7. Bains G, Lohman E, Berk L, Sabir O, Aljehani M, Aljulaymi I, et al. The effect of an 8 week CrossFit type exercise on acute c reactive protein modulation. Medicine \& Science in Sports \& Exercise. 2015;47(5S):372.

8. Brown D, Feito $Y$, Price B, Bycura D, Waugh $K$, Black R, et al. Crossfit Experience Attenuates Heart Rate Variability. Medicine \& Science in Sports \& Exercise. 2015;47(5S):797.
9. Goins JM. Physiological and performance effects of crossfit: The University of Alabama; 2014.

10. McKenzie MJ. Crossfit improves measures of muscular strength and power in active young females. Medicine \& Science in Sports \& Exercise. 2015;47(5S):797.

11. Murawska-Cialowicz E, Wojna J, Zuwala-Jagiello J. Crossfit training changes brain-derived neurotrophic factor and irisin levels at rest, after wingate and progressive tests, and improves aerobic capacity and body composition of young physically active men and women. Journal of physiology and pharmacology: an official journal of the Polish Physiological Society. 2015;66(6):811-21.

12. Hak PT, Hodzovic E, Hickey B. The nature and prevalence of injury during CrossFit training. Journal of strength and conditioning research / National Strength \& Conditioning Association. 2013.

13. Lu A, Shen $P$, Lee $P$, Dahlin B, Waldau B, Nidecker AE, et al. CrossFitrelated cervical internal carotid artery dissection. Emergency radiology. 2015;22(4):449-52.

14. Weisenthal BM, Beck CA, Maloney MD, DeHaven KE, Giordano BD. Injury rate and patterns among CrossFit athletes. Orthopaedic Journal of Sports Medicine. 2014;2(4):2325967114531177.

15. Heinrich KM, Patel PM, O'Neal JL, Heinrich BS. High-intensity compared to moderate-intensity training for exercise initiation, enjoyment, adherence, and intentions: an intervention study. BMC public health. 2014;14:789.

16. History: Find the fittest on earth [Internet]. 2016 b [cited 15/10/2016]. Available from: http://games.crossfit.com/content/history.

17. Butcher SJ, Neyedly TJ, Horvey KJ, Benko CR. Do physiological measures predict selected CrossFit((R)) benchmark performance? Open access journal of sports medicine. 2015;6:241-7.

18. Bellar D, Hatchett A, Judge LW, Breaux ME, Marcus L. The relationship of aerobic capacity, anaerobic peak power and experience to performance in CrossFit exercise. Biology of sport. 2015;32(4):315-20.

19. Statistics From The 2016 Open [Internet]. 2016 c [cited 15/10/2016]. Available from: http://games.crossfit.com/video/statistics-2016-open.

20. Gerhart HD. A comparison of crossfit training to traditional anaerobic resistance training in terms of selected fitness domains representative of overall athletic performance: Indiana University of Pennsylvania; 2013. 